\title{
ВЛИЯНИЕ СВЕТОДИОДНОЙ ФОТОМАТРИЧНОЙ ТЕРАПИИ НА БОЛЕВОЙ СИНДРОМ У ПАЦИЕНТОВ С ПОСТИНСУЛЬТНЫМИ АРТРОПАТИЯМИ ПЛЕЧЕВОГО СУСТАВА
}

\author{
() Келеметова А.Х. ${ }^{1}$, Савин А.А. ${ }^{1}$, Змиевской Г.Н. ${ }^{2}$, Пченичникова В.В. ${ }^{3}$, Савин Л.А. ${ }^{1}$, Семчук И.П. ${ }^{2}$
}

${ }^{1}$ Кафедра нервных болезней Московского государственного медико-стоматологического университета им. А.И. Евдокимова, Москва; ${ }^{2}$ Кафедра биомедицинских технических систем Московского государственного технического университета им. Н.Э. Баумана, Москва;

${ }^{3}$ Городская клиническая больница им. В.В. Вересаева, Москва

\author{
E-mail: $\underline{\text { asiyat87@list.ru }}$
}

В статье представлены результаты использования отечественных светодиодных фотоматричных аппаратов красного цвета свечения при реабилитации пациентов с постинсультными артропатиями. В исследовании приняли участие 88 пациентов в позднем восстановительном и резидуальном периодах ишемического инсульта. Среди больных были выделены 1-я и 2-я основная группы, сопоставимые по возрасту и количеству пациентов. В 1-ю группу вошли больные в позднем восстановительном периоде инсульта, во 2-ю - больные в резидуальном периоде. Контрольную группу образовали пациенты, которым фотоматричная терапия не проводилась. Больным 1-й и 2-й групп проводился курс из 10 сеансов фотоматричной терапии на пораженный сустав. Полученные результаты указали на значительное уменьшение степени выраженности болевого синдрома, нарастание объема движений в плечевом суставе у больных в позднем восстановительном периоде ишемического инсульта по сравнению с резидуальным. В группе контроля без фотоматричного облучения изменения двигательной активности сустава статистически значимыми не были.

Ключевые слова: постинсультные артропатии, реабилитация, фотоматричная терапия, болевой синдром.

\section{THE EFFECT OF PHOTOMATRIX LED THERAPY ON PAIN IN PATIENTS WITH POST-STROKE ARTHROPATHY OF SHOULDER JOINT}

Kelemetova A.H. ${ }^{l}$, Savin A.A. ${ }^{l}$, Zmievskoy G.N. ${ }^{2}$, Pshenichnikova V.V. ${ }^{3}$, Savin L.A. ${ }^{l}$, Semchuk I.P. ${ }^{2}$

${ }^{1}$ Department of Nervous Diseases of A.I. Evdokimov Moscow State University of Medicine and Dentistry, Moscow;

${ }^{2}$ Department of Biomedical Technical Systems of N.E. Bauman Moscow State Technical University, Moscow;

\section{${ }^{3}$ V.V. Veresaev City Clinical Hospital, Moscow}

The article presents the results of using home-produced photomatrix led devices of red glow in the rehabilitation of patients with post-stroke arthropathy. The study involved 88 patients in the late rehabilitation and residual periods of ischemic stroke. Patients were selected into the 1st and 2nd main group matched for age and number of patients. The 1st group included patients in the late recovery period of stroke, the $2^{\text {nd }}$ one - patients in the residual period. The control group was formed by patients who had not undergone photomatrix therapy. Patients of the 1st and 2nd groups underwent a 10-sessions course of photomatrix therapy on the affected joint. The obtained results indicated a significant decrease in the severity of pain, increase in range of motions in the shoulder joint in patients in the late rehabilitation period of ischemic stroke as compared with the residual one. The control group with no photomatrix irradiation had statistically little changes in motor activity of the joint.

Keywords: post-stroke arthropathy, rehabilitation, photomatrix therapy, pain.

В настоящее время врачи всех стран все больше используют в своей практике немедикаментозные методы терапии не только в сочетании с лекарственной терапией, но и как монотерапию.

Прогресс медицинской науки и техники, клинической медицины в значительной степени определяется достижениями в области оптической электроники. Причины широкого применения лазерной и световой энергии во многих областях медицины как эффективного лечебного средства очевидны. С одной стороны, все возрастающая аллергизация населения, а также привыкание к медикаментозным препаратам требуют поиска новых способов патогенетического воздействия на организм пациента.

С другой стороны, экономические преимущества перед лекарственной терапией, широкий спектр действия, достаточно широкая профилак- тическая и терапевтическая эффективность светолазерного излучения (безболезненное, неинвазивное воздействие, при котором в организм не вводится чужеродное вещество) свидетельствуют о перспективности развития этого направления в медицине [1].

Известно, что инсульт является клиническим синдромом, возникающим в рамках таких заболеваний, как атеросклероз, гипертоническая болезнь, ишемическая болезнь сердца, сахарный диабет, ожирение. Постинсультные артропатии являются достаточно частым осложнением, возникающим в раннем восстановительном периоде инсульта. Наиболее часто у $20-40 \%$ больных с постинсультными парезами в первые 4-5 недель после инсульта возникают артропатии плечевого сустава («синдром болевого плеча»). Клинические аспекты постинсультных артропатий много- 
образны в синдромологическом отношении, в интенсивности и выраженности основных их проявлений - двигательного дефицита и наличия болевого синдрома.

По данным ряда исследований, болевой синдром в пораженном суставе имеет место в $100 \%[6,7]$. Боль при постинсультной артропатии связывают с различными факторами, как центральными, так и периферическими. Центральные механизмы относят к поражению зрительного бугра и его связей с теменной областью. Таламические боли обычно возникают сразу после инсульта, усиливаются спонтанно, носят жгучий характер.

Наличие болевого синдрома свидетельствует о вовлечении в патологический процесс вегетативных образований как на сегментарном, так и на местном уровне, ведущих к развитию преимущественно нейродистрофической (больше в плече) и нейроваскулярной патологии (больше в кисти). При этом некоторые авторы обнаруживали изменение микроциркуляции и резорбции радиоактивного йода в левой большой грудной мышце, также подчеркивалось значение венозного застоя в связи с атрофией мускулатуры. Высказывалось мнение и о том, что источник болей в плече может быть и в коже, в зоне фиброзитов и что афферентные стимулы создают гиперчувствительность, в результате чего возникает порочный круг $[5,8]$.

Боль в плече оказывает негативное влияние на функциональное восстановление после инсульта, активность повседневной жизни, качество жизни и продолжительность пребывания в стационаре. Для лечения постинсультных артропатий традиционно используют лекарственные и физические методы воздействия. К лекарственным методам относится применение нестероидных противовоспалительных препаратов, антидепрессантов, противосудорожных препаратов. К нелекарственным методам - импульсная магнитотерапия, электрофорез, дарсонвализация, бальнеопроцедуры, тепло- и холодолечение; массаж и лечебная физкультура. Также в последние годы активно применяются локальные инъекции в зону сустава стероидных препаратов и гиалуроновой кислоты $[2,3]$. Высокая коморбидность пациентов, перенесших инсульт, требует приема множества препаратов.

Учитывая данное обстоятельство, методом выбора остаются местные физические факторы воздействия на пораженный сустав. В 90-х годах 20-го века на кафедре биомедицинских технических систем Московского государственного технического университета им. Н.Э. Баумана появились опытные образцы физиотерапевтических аппаратов, в основе которых лежит лечебный эф- фект красного монохроматического света, излучаемого миниатюрными сверхъяркими светодиодами, расположенными на жестком или гибком основании, повторяющем рельеф облучаемой поверхности.

Аппарат под названием фотоматричного облучателя был внедрен в серийное производство на предприятии Федерального государственного унитарного предприятия Научно-исследовательского института «Полюс» им. М.Ф. Стельмаха. Одними из первых данный метод использовала кафедра нервных болезней Московского государственного медико-стоматологического университета им. А.И. Евдокимова $[1,4]$.

Энергетическая экономичность, простота в применении и малая стоимость по сравнению с лазерными облучателями служат важными преимуществами фотоматричных излучателей. Расширение арсенала немедикаментозных методов лечения с возможностью использования при лечении на дому придает практический интерес дальнейшему внедрению фотоматричной терапии и изучению ее клинических эффектов.

Цель исследования - сравнительное исследование эффективности влияния квазимонохроматического частично когерентного излучения красной области спектра, создаваемого отечественными фотоматричными аппаратами на динамику болевого синдрома на этапах позднего восстановительного и резидуального периодов ишемического инсульта.

\section{МАТЕРИАЛЫ И МЕТОДЫ ИССЛЕДОВАНИЯ}

Исследование проведено на базе московской многопрофильной клинической больницы им. B.В. Вересаева в 2014-2016 гг. у 88 пациентов в позднем восстановительном и резидуальном периодах ишемического инсульта в возрасте от 43 до 83 лет.

Критерии включения: поздний восстановительный и резидуальный периоды ишемического инсульта с наличием болевого синдрома в плечевом суставе паретичной конечности. Критерии исключения: склонность к кровотечениям, прием антикоагулянтов, сенсомоторная афазия, выраженные когнитивные нарушения, легочносердечная и сердечно-сосудистая недостаточность III стадии, злокачественные и доброкачественные новообразования, беременность.

Пациенты имели от одного до трех факторов риска развития инсульта. Наиболее частыми были гипертоническая болезнь, ишемическая болезнь сердца, сахарный диабет, гиперлипидемия, ожирение. Отмечались следующие сопутствующие заболевания: хронический гастрит, язвенная бо- 
лезнь 12-перстной кишки, хронический пиелонефрит, хронический бронхит, узловой зоб.

Среди больных были выделены 1-я и 2-я основная группы, сопоставимые по возрасту и количеству пациентов. В 1-ю группу вошли 32 больных $(50,7 \%)$ в позднем восстановительном периоде инсульта, во 2 -ю - 31 больной $(49,2 \%)$ в резидуальном периоде. Степень выраженности болевого синдрома по визуальной аналоговой шкале варьировала в обеих группах от 5 до 8 баллов.

Контрольную группу образовали 25 пациентов с постинсультной артропатией плечевого сустава, которым фотоматричная терапия не проводилась.

Bce пациенты получали базовую терапию, направленную на вторичную профилактику инсульта, лечебную физкультуру, массаж. Больным 1-й и 2-й групп дополнительно проводился курс из 10 сеансов фотоматричной терапии на пораженный сустав (длительность сеанса 10 минут). Контрольная группа фотоматричную терапию не получала.

Интегрированная оценка неврологического статуса проводилась по шкале инсульта национального института здоровья (NIHSS, National Institutes of health stroke scale) с оценкой степени выраженности пареза в паретичной конечности.

Артропатии были верифицированы по клинико-рентгенологическим данным и не имели клинических и лабораторных эквивалентов воспаления. Оценка объема активных и пассивных движений в паретичных конечностях проводилась с помощью гониометра. Выраженность болевого синдрома оценивали по визуальной аналоговой шкале.

Клинико-психологическое тестирование проводилось всем больным с применением госпитальной шкалы тревоги и депрессии.

Для фотоматричной терапии применяли модификации отечественного аппарата светодиодной терапии «Фотоматрикс» (разработан на кафедре биомедицинских технических систем Московского государственного технического университета им. Н.Э. Баумана). Перед проведением процедуры на сустав наносилась гепариновая мазь производства «Нижфарм».

Статистический анализ проведен с применением программы STATISTICA v. 8.0 (StatSoft Inc., USA). При описании данных при нормальном распределении использовались параметры $\mathrm{M}$ (среднее значение) и $\sigma$ (выборочная дисперсия). Проверка на нормальность проводилась при помощи критерия Шапиро-Уилка. Для каждой из групп сравнивались выборки значений углов, полученных при измерениях до и после лечения, статистическая значимость различий между исследуемыми группами определялась при по- мощи t-критерия Стьюдента при уровне значимости $\mathrm{p}=0,01$.

\section{РЕЗУЛЬТАТЫ ИССЛЕДОВАНИЯ И ИХ ОБСУЖДЕНИЕ}

В результате проведенного лечения отмечено снижение степени выраженности болевого синдрома по визуальной аналоговой шкале у 27 исследованных больных (84,3\%) 1-й группы: с 8 до 5 баллов у 16 исследованных $(59,2 \%)$, с 6 до 3 баллов у 11 больных (40,7\%). Во 2-й группе терапевтический эффект был достигнут у 23 больных: степень выраженности болевого синдрома была снижена с 8 до 6 баллов у $13(56,5 \%)$ и с 6 до 4 баллов у $10(43,4 \%)$ больных.

Тестирование по Госпитальной шкале тревоги и депрессии позволило выявить повышение тревожности у всех из 32 исследованных больных 1-й группы $(100 \%)$ в сочетании с депрессией у 19 больных (59,3\%). Во 2-й группе обнаружено повышение уровня тревожности у 31 больного $(100 \%)$ и наличие депрессии в 18 случаях (58\%). Снижение уровня тревожности и улучшение настроения после проведенного лечения отмечено у 21 больного $(62,5 \%)$ из 1-й группы и у 19 человек $(61,2 \%)$ из 2-й группы.

Сравнительный анализ указал на более выраженное и достоверное понижение уровня болевого синдрома у больных 1-й группы к концу курса фотоматричной терапии по сравнению с результатами, достигнутыми у больных 2-й группы. Объем движений в плечевом суставе до и после лечения в обеих группах представлен в таблице 1.

Согласно табличным данным, критическое значение t-критерия Стьюдента для первой, второй и контрольной групп составляет 2,66, 2,66 и 2,68 соответственно (при уровне значимости $\mathrm{p}=0,01$ ). Налицо статистическая значимость различий между соответствующими показателями в каждой из групп до и после лечения. Таким образом, отмечается эффективность фотоматричной терапии для лечения постинсультных артропатий в позднем восстановительном периоде ишемического инсульта по сравнению с резидуальным. В контрольной группе без фотоматричного облучения изменения двигательной активности сустава статистически значимыми не были.

Достоверно судить о достаточности используемого электромагнитного излучения оптического диапазона в процессе фототерапии можно путем динамической регистрации и критической оценки одного или нескольких частных откликов организма, формирующихся в процессе его взаимодействия с низкоинтенсивным оптическим излучением. 
Объем движений в паретичной конечности до и после лечения

\begin{tabular}{|c|c|c|c|c|c|c|c|c|c|}
\hline \multirow{2}{*}{$\begin{array}{c}\text { Объем движений в } \\
\text { плечевом суставе } \\
\text { (градусы) }\end{array}$} & \multicolumn{2}{|c|}{ 1-я группа (n=32) } & \multirow[t]{2}{*}{$\mathrm{t}$} & \multicolumn{2}{|c|}{ 2-я группа (n=31) } & \multirow[t]{2}{*}{$\mathrm{t}$} & \multicolumn{2}{|c|}{$\begin{array}{c}\text { Группа контроля } \\
(\mathrm{n}=25)\end{array}$} & \multirow[t]{2}{*}{$\mathrm{t}$} \\
\hline & $\begin{array}{c}\text { до } \\
\text { лечения }\end{array}$ & $\begin{array}{l}\text { после } \\
\text { лечения }\end{array}$ & & $\begin{array}{c}\text { до } \\
\text { лечения }\end{array}$ & $\begin{array}{c}\text { после } \\
\text { лечения }\end{array}$ & & $\begin{array}{c}\text { до } \\
\text { лечения }\end{array}$ & $\begin{array}{c}\text { после } \\
\text { лечения }\end{array}$ & \\
\hline $\begin{array}{c}\text { Сгибание в } \\
\text { сагиттальной } \\
\text { плоскости }\end{array}$ & $\begin{array}{l}120,2 \\
\pm 1,5\end{array}$ & $\begin{array}{l}130,9 \\
\pm 1,2\end{array}$ & 5,38 & $\begin{array}{c}124,3 \\
\pm 1,8\end{array}$ & $\begin{array}{l}130,0 \\
\pm 1,3\end{array}$ & 2,56 & $\begin{array}{l}120,6 \\
\pm 1,7\end{array}$ & $\begin{array}{l}121,2 \\
\pm 2,7\end{array}$ & 0,16 \\
\hline $\begin{array}{c}\text { Разгибание в } \\
\text { сагиттальной } \\
\text { плоскости }\end{array}$ & $\begin{array}{l}40,1 \\
\pm 1,1\end{array}$ & $\begin{array}{l}49,7 \\
\pm 1,3\end{array}$ & 5,36 & $\begin{array}{l}35,0 \\
\pm 1,4\end{array}$ & $\begin{array}{l}44,8 \\
\pm 1,3\end{array}$ & 4,93 & $\begin{array}{l}40,1 \\
\pm 1,3\end{array}$ & $\begin{array}{l}40,3 \\
\pm 1,4\end{array}$ & 0,10 \\
\hline $\begin{array}{c}\text { Отведение во } \\
\text { фронтальной } \\
\text { плоскости }\end{array}$ & $\begin{array}{l}149,9 \\
\pm 1,0\end{array}$ & $\begin{array}{l}159,6 \\
\pm 1,3\end{array}$ & 5,72 & $\begin{array}{c}154,9 \\
\pm 1,4\end{array}$ & $\begin{array}{l}160,2 \\
\pm 1,4\end{array}$ & 2,61 & $\begin{array}{l}149,9 \\
\pm 1,2\end{array}$ & $\begin{array}{l}150,5 \\
\pm 2.3\end{array}$ & 0,21 \\
\hline
\end{tabular}

Получив возможность воздействия на конкретного пациента в строго оптимальной для него дозе (которая будет устанавливаться достижением некоего баланса между интенсивностью и продолжительностью воздействия, с одной стороны, и наступлением момента максимального восстановления нарушенной функции - по количественным показателям отклика на это воздействие - с другой), можно будет оградить больного от излишнего (как минимум, бесполезного, и, как максимум, вредного) воздействия излучения реабилитационного устройства на организм, а само устройство - от неэффективной эксплуатации, установив рациональный режим его использования, что тоже представляется немаловажным полезным фактором исследований.

\section{ЛИТЕРАТУРА}

1. Буйлин В.А., Ларюшин А.И., Никитина М.В. Светолазерная терапия. Руководство для врачей. Тверь : Издательство «Триада», 2004. - С. 3-21, 157-159.

2. Гурленя А.М., Багель Г.Е., Смычек В.Б. Физиотерапия в неврологии. - М : Медицинская литература, 2008. - C. 54-55.

3. Епифанов В.А., Епифанов А.В. Реабилитация в неврологии. - М.: ГЭОТАР-Медиа, 2013. С. 9-21.
4. Келеметова А.Х., Савин А.А., Пшеничникова В.В., Змиевской Г.Н., Семчук И.П., Савин Л.А., Филатов B.B. Применение светодиодной фотоматричной терапии при постинсультных артропатиях плечевого сустава // Журнал Неврологии и Психиатрии им. С.С. Корсакова. - 2016 - Т. 116, № 6. C. 20-24.

5. Gilmore P.E., Spaulding S.J., Vandervoort A.A. Hemiplegic shoulder pain: implications for occupational therapy treatment // Can J Occup Ther. - 2004. Vol. 71, N 1. - $\quad$ P. 36-46. $\quad$ - doi: 10.1177/000841740407100108.

6. Lim J.Y., Koh J.H., Paik N.J. Intramuscular botulinum toxin-A reduces hemiplegic shoulder pain: a randomized, double-blind, comparative study versus intraarticular triamcinolone acetonide // Stroke. - 2008. Vol. 39, N 1. - P. 126-131. - doi: 10.1161/STROKEAHA.107.484048.

7. Merolla G., Bianchi P., Porcellini G. Ultrasoundguided subacromial injections of sodium hyaluronate for the management of rotator cuff tendinopathy: a prospective comparative study with rehabilitation therapy // Musculoskelet Surg. - 2013. - Vol. 97, Suppl. 1. - P. 49-56. - doi: 10.1007/s12306-0130259-y.

8. Penning L.I., de Bie R.A., Walenkamp G.H. The effectiveness of injections of hyaluronic acid or corticosteroid in patients with subacromial impingement: a three-arm randomised controlled trial // J Bone Joint Surg Br. - 2012. - Vol. 94, N 9. - P. 1246-1252. doi: 10.1302/0301-620X.94B9.28750. 